Artigo

\title{
O uso de um painel restrito de anticorpos monoclonais no diagnóstico diferencial das síndromes linfoproliferativas
}

Irene Lorand-Metze ${ }^{1}$

Ana C. Chiari ${ }^{2}$

Fernanda G. Pereira ${ }^{3}$
O uso da imunofenotipagem, ao lado da morfologia do sangue periférico, é um elemento imprescindível no diagnóstico diferencial das síndromes linfoproliferativas. Empregamos com este propósito um painel de anticorpos monoclonais: CD19/CD10, CD20/CD5, CD23, CD3/CD4, CD3/CD8, além de anticorpos contra cadeias leves de imunoglobulina de superfícielidos em citometria de fluxo. Aplicamos este painel em 44 pacientes do nosso Serviço usando como confirmação a morfologia do sangue periférico. Em 29 pacientes foi encontrado 0 fenótipo típico de Leucemia Linfóide Crônica-B e dois casos foram Leucemia Linfóide Crônica-T. Em oito casos o imunofenótipo foi insuficiente para fechar o diagnóstico que foi confirmado pela morfologia do sangue periférico: seis casos de imunocitoma e dois de leucemia prolinfocítica. Nos cinco casos de linfoma de células do manto, em três deles a imun ofenotipagem do sangue periférico ou do aspirado de linfonodo fechou o diagnóstico. Nos outros dois o diagnóstico foi confirmado pela biópsia de linfonodo. Estes achados ressaltam o papel da imunofenotipagem no diagnóstico correto das síndromes linfoproliferativas. 0 painel usado, apesar de pequeno, foi suficiente, necessitando do apoio da morfologia em poucos casos. Rev.bras.hematol.hemoter., 2000, 22(1):41-45

Palavras-chave: sín dromes linfoproliferativas, leucemia linfoide crônica, diagnóstico, imunofenotipagem

\section{Introdução}

As síndromes linfoproliferativas formam um grupo de neoplasias que tem seu diagnóstico baseado em geral na morfologia celular de sangue periférico. Muitas vezes esta morfologia é similar, dificultando uma adequada classificação e consequentemente a escolha do tratamento. 0 uso da imunofenotipagem, ao lado da morfologia do sangue periférico é um instrumento imprescindível para a realização do diagnóstico diferencial.

A leucemia linfóide crônica (LLC) é definida a partir da linfocitose mantida no sangue periférico acima de $10 \times 10^{9} / \mathrm{l}$, sem causa aparente. Encontra-se uma linfocitose ao mielograma acima de $40 \%$ (1). Estes achados podem ocorrer em pacientes assintomáticos sem achado de exame físico. Mas pode também haver graus variados de linfonodomegalia ou hepatoesplenomegalia.

1 - Professor Titular, Depto. de Clínica Médica, Faculdade de Ciências Médicas - UNICAMP

2 - Médica Residente Depto de Clínica Médica, Faculdade de Ciências Médicas - UNICAMP

3 - Bióloga, Laboratório de Marcadores Celulares - Hemocen tro - UNICAMP

Correspondência para: Profa. Dra. Irene Lorand-Metze

Hemocentro - UNICAMP. Caixa Postal 6198. CEP: 13081-970. Campinas. SP

Fax: (19) 788-8750 
A morfologia dos linfócitos no sangue periférico pode ser típica, mas pode ocorrer número variável de prolinfócitos, além de algumas células blásticas (1-4). A LLC tem sido definida a partir do seu imunofenótipo: coexpressão de um marcador pan-B (CD19 ou CD20) com o CD5 (normalmente encontrado nos linfócitos T), CD 23 e expressão monoclonal fraca de imunoglobulinas de superfície. As células da LLC são geralmente negativas para $\mathrm{FMC7}, \mathrm{CD} 79 \mathrm{~b}$ e CD22 (1-5). Estes dois últimos são considerados marcadores $B$ muito específicos. 0 imunofenótipo, muitas vezes mais até que a morfologia das células, tem sido útil para o diagnóstico diferencial com outras síndromes linfoproliferativas crônicas (linfomas indolentes leucemizados) tais como imunocitoma ou macroglobulinemia de Waldenström, linfoma folicular, linfoma de células do manto, tricoleucemia e linfoma esplênico.

0 nosso objetivo foi o de testar o valor de um painel muito pequeno de anticorpos monoclonais aliado à morfologia do sangue periférico no diagnóstico da LLC e seu diagnóstico diferencial com outras síndromes linfoproliferativas.

\section{Casuística e Métodos}

Entraram no estudo pacientes com síndromes linfoproliferativas vistos no Hemocentro da UNICAMP nos últimos 12 meses. O diagnóstico foi feito pelos dados clínicos, hemograma, mielograma e biópsia ou aspirado de linfonodo se necessário. 0 estadiamento foi feito segundo Binet (1).

o diagnóstico final foi baseado na morfologia do sangue periférico e/ou linfonodo e um painel de anticorpos usados para imunofenotipagem que compreendeu: CD 19/ CD 10, CD20/CD5, CD23, CD3/CD 4, CD3/CD8 e anti kappa/anti-lambda (para imunoglobulina de superfície). Este painel foi aplicado em leucócitos do sangue periférico separados em coluna de Ficoll-Hypaque. Os leucócitos foram lavados em PBS e incubados com os pares de anticorpos acima (Becton Dickinson - USA). A leitura foi feita por citometria de fluxo num equipamento FacScalibur (Becton Dickinson) com aquisição de 10000 células. Os critérios diagnósticos estão na tabela 1 . Os resultados da citometria foram comparados com a morfologia do sangue periférico e com o diagnóstico histológico do linfonodo nos casos em que havia este dado.

\section{Resultados}

Entraram no estudo 44 pacientes. Destes, 29 tiveram o imunofenótipo e a morfologia sanguínea de LLC. Destes, 16 tiveram restrição de cadeia leve kappa e 13 tiveram cadeia lambda monoclonal. Em 15 casos, a imunofenotipagem apontou para um diagnóstico diferente da LLC. Nestes, foi necessário o uso conjugado do estudo morfológico e fenotípico para se chegar a um diagnóstico final (Tabela 2). A morfologia do sangue periférico fechou o diagnóstico em oito destes casos (seis de imunocitoma e dois de leucemia prolinfocítica). 0 diagnóstico foi confirmado pela biópsia de linfonodo em três dos cinco casos de linfoma de células do manto, o que ocorreu nos dois outros com o aspirado do linfonodo com imunofenotipagem. Em dois casos ainda, o diagnóstico final foi o de LLC-T.

Tabela 1. Critérios usados para a interpretação da imunofenotipagem

\begin{tabular}{l|c|c|c|c|c|c}
\hline & CD10 & CD5/43 & CD23 & CD20 & SIg & \\
\hline LLC & - & + & + & + & Fraco & \\
LPL & - & \pm & \pm & + & Forte & FMC7 \\
IC & - & \pm & \pm & + & Forte & CD38 \\
LCM & \pm & + & - & + & & \\
LZM & - & \pm & - & + & & \\
FCC & + & - & \pm & + & & \\
\hline
\end{tabular}

LLC = leucemia linfoide crônica, LPL = leucemia prolinfocítica, IC = imunocitoma, LCM = linfoma de células do manto, LZM = linfoma esplênico de zona marginal, FCC = linfoma folicular. Slg = imunoglobulina de superfície. 
Tabela 2. Pacientes com imun ofenótipo diferente da LLC clássica

\begin{tabular}{l|c|c|c|c|c|c|c|c|c}
\hline Paciente & CD3 & CD4 & CD8 & CD19 & CD5 & CD23 & CD10 & $\begin{array}{c}\text { cadeia } \\
\text { leve }\end{array}$ & Diagnóstico \\
\hline AV & + & + & - & - & & - & - & - & LLC-T \\
RP & + & + & - & - & & - & - & - & LLC-T \\
ARM & - & - & - & + & - & + & - & lambda & IC \\
EA & - & - & - & + & - & & - & kappa & IC \\
LPS & - & - & - & + & + & + & - & lambda & IC \\
GBO & - & - & - & + & - & + & - & kappa & IC \\
AF & - & - & - & + & - & \pm & - & kappa & IC \\
R.L & - & - & - & + & \pm & + & - & & IC \\
AO & - & - & - & + & + & \pm & - & kappa & LPL \\
MRS & - & - & - & + & + & - & - & lambda & LPL \\
MS & - & - & - & + & + & - & - & lambda & LCM \\
ED & - & - & - & + & + & - & - & & LCM \\
AFB & - & - & - & + & + & - & - & lambda & LCM \\
BMF & - & - & - & + & + & - & - & kappa & LCM \\
AAP & & & - & - & + & - & - & lambda & LCM \\
\hline
\end{tabular}

LLC = leucemia linfoide crônica, $L P L=$ leucemia prolinfocítica, IC = imunocitoma, $L C M=$ linfoma de células do manto, LZM = linfoma esplênico de zona marginal, $F C C=$ linfoma folicular. Slg = imunoglobulina de superfície.

\section{Discussão}

Os procedimentos diagnósticos propostos foram facilmente exequíveis em todos os casos, desde que o paciente tivesse leucocitose acima de $15 \times 10^{9} /$, critério exigido para o diagnóstico de LLC. O painel de anticorpos monoclonais usados, embora pequeno, permitiu separar as diversas entidades, usando a confirmação pela morfologia. Num passo inicial, permitiu separar as síndromes linfoproliferativas de origem $B$ das T. Estas últimas não são frequentes no nosso meio, mas têm comportamento clínico e resposta a tratamento próprios. Além disso, frequentemente têm relação com a infecção pelo HTLV-1 (6), o que não foi o caso dos nossos pacientes.

O diagnóstico de LLC não ofereceu dificuldades mesmo na presença de linfocitoses pouco elevadas, devido ao seu fenótipo aberrante CD20/CD5, associando a positividade para CD 23, além de imunoglobulina de superfície monoclonal. Estas características possibilitam distinguir as células da LLC de linfocitoses reacionais. Tem-se discutido na literatura a existência de casos de LLC CD5 negativas que poderia ocorrer em 0-36\% dos casos $(7,8)$. Porém, com critérios diagnósticos mais exatos, isto deve ocorrer em apenas 2\%. De acordo com a morfologia do sangue periférico, o imunocitoma leucemizado é o diagnóstico diferencial mais frequente de LLC (9). Nestes casos pode-se encontrar positividade para CD5. No entanto, a expressão de CD20 e de imunoglobulina de superfície é muito mais acentuada. A morfologia das células circulantes pode ajudar, com a presença de células linfoplasmocitoides ou plasmócitos. Diferente da LLC, no imunocitoma encontramos a positividade para imunoglobulinas intracitoplasmáticas, FMC7 e CD38, o que não foi pesquisado no nosso material. A expressão de CD38 é uma característica da linhagem plasmocítica, mas tem sido descrita em mais de $20 \%$ dos casos de LLC (10), estando associado à ausência de mutação somática da região variável da cadeia pesada de imunoglobulina e a mau 
prognóstico. Por todas estas razões seria importante acrescentar o CD38 ao painel proposto. É muito importante o diagnóstico diferencial entre LLC e imunocitoma leucemizado, não só pela presença neste de paraproteínas e amilóide, como também por uma pior resposta à quimioterapia.

A leucemia prolinfocítica tem um fenótipo semelhante ao do imunocitoma, embora não apresente imunoglobulinas intracitoplasmáticas nem positividade para $\operatorname{CD} 38(2,4,5)$. Tem, porém, uma morfologia característica, representada por linfócitos grandes com nucléolo muito evidente. Na nossa casuística, um dos pacientes foi CD5 positivo. Ambos os casos tiveram forte expressão de imunoglobulinas de superfície. A leucemia prolinfocítica é pouco frequente, cursa com grandes linfocitoses e esplenomegalia volumosa. Sua resposta à quimioterapia é pobre, sendo que as únicas armas terapêuticas eficazes têm sido a esplenectomia, a radiação esplênica e 0 uso dos análogos das purinas $(11,12)$.

0 diagnóstico diferencial entre LLC e o linfoma de células do manto é muito importante. Embora seja considerado indolente na classificação de Kiel, apresenta frequentemente ao diagnóstico um caráter muito disseminado, com grande massa tumoral. Responde apenas à quimioterapia usada em linfomas agressivos. O seu imunofenótipo é caracteristicamente CD20/CD5, sendo negativo para CD23, o que facilita o seu diagnóstico em sangue periférico ou aspirado de linfonodo e pode ser usado para estudos de doença residual mínima. Pode ainda ser positivo para CD43 e apresentar rearranjo de bcl-1 (2,8). 0 diagnóstico também pode ser confirmado pela biópsia de linfonodo.

$\mathrm{Não}$ foi incluído na nossa casuístca nenhum caso de tricoleucemia. Esta é uma síndrome linfoproliferativa rara, cujo diagnóstico é geralmente feito por biópsia de medula óssea ou esplenectomia, pois os pacientes apresentam pancitopenia e esplenomegalia. 0 seu imunofenótipo é CD22, FMC7, CD25, CD11C, mas o seu marcador mais específico é o CD103 (2). Na histologia de medula encontramos a positividade para DBA44.

Assim, vemos que o uso de marcadores imunológicos é fundamental para o correto diagnóstico das síndromes linfoproliferativas crônicas, e possibilita o tratamento adequado de cada uma delas.

\section{The value of a small panel of monoclonal antibodies for the differential diagnosis of lymphoproliferative syndromes.}

Irene Lorand-Metze, Ana C. Chiari, Fernanda G. Pereira

\section{Abstract}

The immunological profileand the morphology of lymphoid cells are the main diagnostic clues for a correct differential diagnosis of chronic lymphoproliferativedisorders. In the present study, we used a small panel of monoclonal antibodies for this purpose: CD19/CD10, CD20/CD5, CD23, CD3/CD4, CD3/CD8, kappa chain/lambda chain (for the detection of surfaceimmunoglobulin). This panel wasapplied in 44 patients seen at our Service, using peripheral blood or lymph node morphology as a confirmatory element. Among them 29 had a typical immunologic profile of B-CLL (16 with kappa light chain and 13 with lamba chain restriction) and 2 were T-CLL. In 8 cases, immunologic study needed peripheral blood morphology for diagnostic confirmation: 6 cases of immunocytoma and 2 prolymphocytic leukemias. The 5 patients with mantle cell lymphoma were diagnosed based on the immunologic profile of peripheral blood or lymph nodeaspirates. The present observation underlines the importance of the immunophenotype in the correct diagnosis of thechronic lymphoproliferative syndromes. The small panel used was sufficient, when morphological examination of peripheral blood or lymph node was used for diagnostic confirmation if necessary.

Rev.bras.hematol.hemoter., 2000, 22(1):41-45

Key words: lymphoproliferatives syndromes, chronic Iymphocitic leukemia, diagnosis, immunophen otyping

\section{Referências bibliográficas}

1. Dighiero G., Binet J.L. Chronic Iymphocytic leukemia. Hematol Cell 
Ther 1996; 38: S41-S61.

2. Garand R., Robillard N. Immunophen otypic characterization of acute leukemias and chronic lymphoproliferative disorders. Hematol Cell Ther 1996; 38:471-486.

3. Matutes E., Ow usu-Ankomah K., Morilla R., et al. The immunological profile of B-cell disorders and proposal of a scoring system for the diagn osi s of CLL. Leukemia 1994; 8: 1640-1645.

4. General Haematology Task Force of BCSH Immunophenotyping in the diagnosis of chronic lymphoproliferativedisorders. J Clin Pathol 1994; 47: 871-875.

5. DiGiuseppe J.A, Borowitz M.J. Clinical utility of flow cytometry in the chronic lymphoid leukemias. Semin Oncol 1998; 25: 6-10.

6. Oliveira M.S.P., Loureiro P., Bittencourt A, et al. Geographic diversity of adult T-cell leukemia/lymphoma in Brazil. IntJ Cancer 1999; 83: 291-298.

7. Huang J.C., Finn W.G., Goolsby C.L., Variakojis D., Peterson L.A C. CD5- small Bcell leukemias are rarely classifiable as chronic lymphocytic leukemia. Am J Clin Pathol 1999; 111: 123-130.

8. Lydard P.M., Jewell A.P., Jamin C, Youinou P.Y. CD5 B cells and B-cell malignancies. Curr Opin Hematol 1999; 6:30-36.

9. Pangalis G.A, Angelopoulou M.K., Vassilakopoulos T.P., Slakantaris M.P., Kittas C. B-chronic lymphocytic leukemia, small Iymphocytic Iymphoma, and lymphoplaspacytic lymphoma, including Walden ström's macroglobulinemia. Semin Hematol 1999; 36: 104-114.

10. Damle R.N., Wasil T., Fais F. et al. Ig V gene mutation statusand CD38 expression asnovel progn ostic indicators in chronic lymphocytic leukemia. Blood 1999; 94: 1840-1847.

11. Lorand I., Souza C.A, Kneubil D.B. Leucemia prolinfocítica: respuesta favorable a radioterapia esplénica. Sangre 1981; 26: 262.

12 . Lorand-Metze I., Oliveira G.B., Aranha F.J. Treatment of prolymphocytic leukemia with cladribine. Ann Hematol 1998; 76: 85-86.

Recebido: $25 / 01 / 2000$

Aceito: 29/02/2000 